\title{
Article
}

\section{The Value of Heart Rhythm Complexity in Identifying High-Risk Pulmonary Hypertension Patients}

\author{
Shu-Yu Tang ${ }^{1,2}$, Hsi-Pin Ma ${ }^{3}$, Chi-Sheng Hung ${ }^{1}$, Ping-Hung Kuo ${ }^{1}{ }^{\mathbb{D}}$, Chen Lin ${ }^{4}$, Men-Tzung Lo ${ }^{4}$, \\ Hsao-Hsun Hsu ${ }^{5}$, Yu-Wei Chiu 6,7, Cho-Kai Wu ${ }^{1}$, Cheng-Hsuan Tsai 1,8,*, Yen-Tin Lin ${ }^{9, *}$, Chung-Kang Peng $10 \mathbb{D}$ \\ and Yen-Hung Lin 1 ,*
}

\section{check for}

updates

Citation: Tang, S.-Y.; Ma, H.-P.; Hung, C.-S.; Kuo, P.-H.; Lin, C.; Lo, M.-T.; Hsu, H.-H.; Chiu, Y.-W.; Wu, C.-K.; Tsai, C.-H.; et al. The Value of Heart Rhythm Complexity in Identifying High-Risk Pulmonary Hypertension Patients. Entropy 2021, 23, 753. https://doi.org/10.3390/ e23060753

Academic Editor: Vitor Engrácia Valenti

Received: 26 May 2021

Accepted: 12 June 2021

Published: 15 June 2021

Publisher's Note: MDPI stays neutral with regard to jurisdictional claims in published maps and institutional affiliations.

Copyright: (C) 2021 by the authors Licensee MDPI, Basel, Switzerland. This article is an open access article distributed under the terms and conditions of the Creative Commons Attribution (CC BY) license (https:// creativecommons.org/licenses/by/ $4.0 /)$.
1 Department of Internal Medicine, National Taiwan University Hospital and National Taiwan University College of Medicine, Taipei 100, Taiwan; y03833@ms1.ylh.gov.tw (S.-Y.T.); 009578@ntuh.gov.tw (C.-S.H.); kph712@ntuh.gov.tw (P.-H.K.); chokaiwu@ntuh.gov.tw (C.-K.W.)

2 Department of Internal Medicine, National Taiwan University Hospital Yun-Lin Branch, Yun-Lin 640, Taiwan

3 Department of Electrical Engineering, National Tsing Hua University, Hsinchu 300044, Taiwan; hp@ee.nthu.edu.tw

4 Department of Biomedical Sciences and Engineering, National Central University, Taoyuan City 330, Taiwan; clin@ncu.edu.tw (C.L.); mzlo@ncu.edu.tw (M.-T.L.)

5 Department of Surgery, National Taiwan University Hospital and National Taiwan University College of Medicine, Taipei 100, Taiwan; 008295@ntuh.gov.tw

6 Department of Computer Science and Engineering, Yuan Ze University, Taoyuan City 330, Taiwan; dtmed005@saturn.yzu.edu.tw

7 Cardiology Division of Cardiovascular Medical Center, Far Eastern Memorial Hospital, New Taipei City 220, Taiwan

8 Department of Internal Medicine, National Taiwan University Hospital Jin-Shan Branch, New Taipei City 220, Taiwan

9 Department of Internal Medicine, Taoyuan General Hospital, Taoyuan City 330, Taiwan

10 Division of Interdisciplinary Medicine and Biotechnology, Beth Israel Deaconess Medical Center/Harvard Medical School, Boston, MA 02215, USA; ckpeng@comcast.net

* Correspondence: d09421005@ntu.edu.tw (C.-H.T.); b91401008@ntu.edu.tw (Y.-T.L.); yenhunglin@ntuh.gov.tw (Y.-H.L.)

Abstract: Pulmonary hypertension (PH) is a fatal disease-even with state-of-the-art medical treatment. Non-invasive clinical tools for risk stratification are still lacking. The aim of this study was to investigate the clinical utility of heart rhythm complexity in risk stratification for $\mathrm{PH}$ patients. We prospectively enrolled $54 \mathrm{PH}$ patients, including 20 high-risk patients (group A; defined as WHO functional class IV or class III with severely compromised hemodynamics), and 34 low-risk patients (group B). Both linear and non-linear heart rate variability (HRV) variables, including detrended fluctuation analysis (DFA) and multiscale entropy (MSE), were analyzed. In linear and non-linear HRV analysis, low frequency and high frequency ratio, DFA $\alpha 1$, MSE slope 5, scale 5, and area 6-20 were significantly lower in group A. Among all HRV variables, MSE scale 5 (AUC: 0.758) had the best predictive power to discriminate the two groups. In multivariable analysis, MSE scale $5(p=0.010)$ was the only significantly predictor of severe $\mathrm{PH}$ in all HRV variables. In conclusion, the patients with severe PH had worse heart rhythm complexity. MSE parameters, especially scale 5, can help to identify high-risk $\mathrm{PH}$ patients.

Keywords: pulmonary hypertension; heart rate variability; non-linear analysis; detrended fluctuation analysis; multiscale entropy

\section{Introduction}

Pulmonary hypertension $(\mathrm{PH})$ is a progressive, complex, and fatal disease. It involves heterogenous etiologies and different mechanisms [1], and eventually leads to right heart failure. The mortality of $\mathrm{PH}$ patients is high even after contemporary treatment [2]; however, timely and intensive management can improve outcomes even in high-risk patients. In 
addition, the dynamic adjustment of $\mathrm{PH}$ medications, based on disease status during followup, also plays an important role in PH management [3-5]. Therefore, a useful tool for PH risk stratification is urgently needed to guide $\mathrm{PH}$ treatment. Several prognostic factors of PH have been verified, including sex, exercise tolerance, right heart hemodynamics, and functional performance [6-8], and they have been applied in different prediction models.

In 2015, the European Society of Cardiology (ESC)/European Respiratory Society (ERS) $\mathrm{PH}$ guidelines first proposed a dynamic PH risk assessment tool, including a combination of imaging, biologic, hemodynamic, performance status, and clinical conditions [1]. This tool has shown good survival prediction between different risk groups [9,10]; however, it requires right heart hemodynamic measurements, which are invasive and difficult to apply for continuous monitoring of $\mathrm{PH}$ severity in clinical practice. Therefore, in this study, we propose a non-invasive and convenient tool for $\mathrm{PH}$ risk assessment derived from heart rate variability (HRV), namely, heart rhythm complexity analysis.

Heart rhythm complexity analyzes the complexity of changes in heart rate using non-linear methods, and it has been shown to have better predictive value for the diagnosis of PH and heart failure outcomes [11-13] than traditional HRV linear analysis [14]. In our previous study, we found that heart rhythm complexity was decreased in $\mathrm{PH}$ patients, and that it was useful to differentiate PH patients from normal populations [13]. However, whether heart rhythm complexity is useful in the risk stratification of PH patients is unknown. Therefore, we designed this study to investigate the clinical application of heart rhythm complexity in the risk stratification of $\mathrm{PH}$ patients.

\section{Materials and Methods}

\subsection{Patients}

We prospectively enrolled 54 Taiwanese patients with $\mathrm{PH}$ from a single center, including 35 with pulmonary arterial hypertension (PAH) and 19 with chronic thromboembolic pulmonary hypertension (CTEPH) from May 2012 to April 2018. Based on the ESC guidelines [1], the diagnosis of $\mathrm{PH}$ was made when the patient had suspicious clinical symptoms, and with mean pulmonary arterial pressure (mPAP) no less than $25 \mathrm{mmHg}$ in right heart catheterization. The World Health Organization (WHO) recognizes five groups of $\mathrm{PH}$, categorized by etiology or comorbidity. The PAH was in the WHO group 1 and CTEPH was in the WHO group 4 . The diagnosis of WHO group 1 was made when the pulmonary artery wedge pressure (PAWP) less than $15 \mathrm{mmHg}$, and pulmonary vascular resistance (PVR) more than 3 Wood Units, and without the evidence of left heart disease. The diagnosis of WHO group 4 was made when the ventilation-perfusion lung scintigraphy showed filling defects in $\mathrm{PH}$ patients with the same hemodynamics criteria in right heart catheterization as in PAH. PAH and CTEPH have similar pathophysiological mechanisms as vascular arteriopathy [15], presenting as elevated pre-capillary vessel pressure and pulmonary vascular resistance [16]. Other types of PH may involve complex disease mechanisms, such as lung disease or heart failure, which may result in patient heterogeneity, and were excluded from this study. Therefore, we only enrolled these two PH subgroups in the present study to avoid the confounding influence of other pathophysiologies.

All patients underwent echocardiography, blood sampling, right heart catheterization, and 24-h ambulatory electrocardiogram Holter recording. A full record of medical history of each patient was documented, including dyslipidemia, diabetes mellitus, hypertension, and coronary artery disease. The prescription of $\mathrm{PH}$ specific medication was recorded as well. The diagnosis of $\mathrm{PH}$ was confirmed by right heart catheterization, based on the ESC guidelines [1]. Parameters, including MPAP, PAWP, right atrial pressure, cardiac output, and cardiac index, were all recorded during right heart catheterization. Blood sampling was obtained during the right heart catheterization. We tested N-terminal probrain natriuretic peptide (NT-proBNP), hemoglobin, and creatinine. Both echocardiogram and Holter recordings were performed 2 months before or after right heart catheterization. A six-minute-walk-distance (6MWD) test was recorded 3 months before or after right heart catheterization if the patient was tolerable. 
The patients were divided into two groups based on PH severity [17]. The highrisk group was defined as (1) WHO functional class IV or (2) WHO functional class III with severely compromised hemodynamics (right atrial pressure: Pra $>15 \mathrm{mmHg}$ or cardiac index $<2.0 \mathrm{~L} \cdot \mathrm{min}^{-1} \cdot \mathrm{m}^{2}$ ). PH patients in WHO functional class I to II and in WHO functional class III without severely compromised hemodynamics were in the low-risk group $[18,19]$. There were 20 patients in the high-risk group (group A) and 34 patients in the low-risk group (group B).

This study was approved by the Institutional Review Board of National Taiwan University Hospital (approval numbers NTUH REC No. 201003042R), and all subjects provided written informed consent. All research was performed in accordance with relevant guidelines and regulations. Reporting of this study followed the Strengthening the Reporting of Observational Studies in Epidemiology statement [20].

\subsection{Echocardiogram}

All patients underwent typical transthoracic echocardiography (iE33 x MATRIX Echocardiography System, Philips, Amsterdam, Netherlands). According to the recommendations of the American Society of Echocardiography, tricuspid regurgitation pressure gradient (TRPG) was measured as the peak flow velocity of tricuspid regurgitation (TRV) using a simplified Bernoulli equation: TRPG $=4 \times \mathrm{TRV}^{2}$. Left ventricular ejection fraction in M-mode was measured in the parasternal long axis view [21]. The presence of pericardial effusion or not was documented as well.

\subsection{4-h Holter Recording and Data Processing}

All patients received 24-h ambulatory electrocardiogram Holter recording (Zymed DigiTrak Plus 24-Hour Holter Monitor Recorder and DigiTrak XT Holter Recorder 24-Hour, Philips, Amsterdam, Netherlands) and maintained their original daily activity during the examination without specific limitations. The data were automatically processed using an algorithm and then checked by two technicians. The adopted length of RR Intervals for both linear and non-linear HRV analysis was 4-h and the following criteria was met: (1) between 9 a.m. and 6 p.m.; (2) patients were in awake status; and (3) without sudden increases in heart rate of more than $40 \mathrm{bpm}$ within $1 \mathrm{~min}$ to avoid the potential influences of sleep and strong physical activities for both linear and nonlinear analysis, while maintaining enough time length for nonlinear analysis. HRV parameters were processed automatically with MATLAB software.

Nonstationarity can significantly compromise the results of complexity analysis especially for the arrhythmias [22]. We identified the QRS complexes by implementing an adaptive threshold, based on the concept of order-statistic filter, which can be effective for wide ranges and variations of heart rate [23]. Then, the detected QRS peaks were visually inspected to avoid automatic misdetections, and the arrhythmic beats, such as atrial premature contractions, and ventricular premature contractions were removed and replaced by the estimated RR using cubic spline interpolation. Only the RR intervals segments with less than 5\% removal were used in this study. In addition, to avoid an unwanted effect of external nonstationarity, we used the empirical mode decomposition method to de-trend the RR series for the oscillation longer than $1 \mathrm{~h}$ [24].

\subsection{Linear HRV Analysis}

The interpolated normal-to-normal RR intervals were further used to calculate conventional linear HRV based on the recommendations of the North American Society of Pacing Electrophysiology and the European Society of Cardiology [25]. We analyzed time domain and frequency domain parameters. Time domain analysis included mean RR interval (mean RR), standard deviation of RR interval (SDRR), percentage of absolute differences in normal RR intervals greater than $20 \mathrm{~ms}\left(\mathrm{pNN}_{20}\right)$, and percentage of absolute differences in normal RR intervals greater than $50 \mathrm{~ms}\left(\mathrm{pNN}_{50}\right)$, representing autonomic nervous system modulation of heart rhythm. The RR intervals were first linearly interpolated at $4 \mathrm{~Hz}$ and 
fast Fourier transform was carried out on the resampled signals. The summation of the power over a different frequency band, including high frequency, (HF, 0.15-0.4 Hz), low frequency (LF, 0.04-0.15 Hz), and very low frequency (VLF, 0.003-0.04 Hz), were calculated as the frequency domain parameters.

\subsection{Non-Linear HRV Analysis}

For non-linear HRV analysis, we applied the multiscale entropy (MSE) and detrended fluctuation analysis (DFA) to quantify the fractal properties of the signals, such as longterm memory effect and information richness over different time-scales. DFA was used to quantify the correlation property of inter-beat interval dynamics in the time series, while eliminating the external nonstationarity by removing the linear-fitted trends in a different time-scale (box-size) [26]. Initially, the average of the normal-to-normal intervals was removed. The resultant signal was then integrated and then divided into segments of equal samples $n$. The fluctuation $F(n)$ of the signal in the corresponding time-scale $n$ was calculated by the root-mean-square of the integrated signal after removing the fitted trends in the segments. The procedure was then repeated in a different time-scale from a small box-size (e.g., $\mathrm{n}=4$ ) to a large box-size (e.g., $\mathrm{n}=100)$. On a double log graph of $\mathrm{F}(\mathrm{n})$ and the corresponding box-size (n), the slope of the line was defined as the $\alpha$ exponent, representing the fractal correlation property of the time series. Both short-range ( $\alpha 1: 4-11$ beats) and long-range time scales ( $\alpha 2$ : 11-64 beats) were calculated [27].

MSE analysis is used to measure the complexity of the finite length time series. Compared to a traditional single scale, entropy estimation only measures the degree of regularity on a single time scale; MSE uses "coarse graining" proceeding multiple time scales and provides information richness over different time-scales as the complexity of the system. To estimate entropy, we calculated sample entropy (SampEn) for each coarse-grained time series, and then plotted this as a function of the scale factor. To quantify the complexity of the heartbeat dynamics, in short and long time scales, we calculated the entropy values of scale 5 (scale 5), the linear-fitted slope of scale 1-5 (slope 5), area under the MSE curve for scale 1-5 (area 1-5), and area under the MSE curve for scale 6-20 (area 6-20) [28].

\subsection{Statistical Analysis}

Continuous variables were expressed as mean \pm standard deviation for normally distributed variables, and median (interquartile range, 25th and 75th percentiles) for nonnormally distributed variables. Categorical variables were expressed as absolute and relative frequencies (percentage). Comparisons were made using the independent $t$-test and the Mann-Whitney U test between two groups. The chi-square test or Fisher's exact test was used to examine differences between proportions. The discrimination abilities of HRV parameters to high-risk $\mathrm{PH}$ were assessed using the receiver operating characteristic (ROC) curve analysis. Logistic regression analysis was used to assess associations between variables and high-risk PH. Significant determinants in univariable logistic regression analysis $(p<0.05)$, including creatinine, PAH group 1 , serum creatinine level, plasma NT-proBNP level, mPAP, PVR, LF/HF ratio, DFA $\alpha 1$, slope 1-5, MSE scale 5, and area 6-20, were then tested in multivariable logistic regression analysis with stepwise selection to identify independent factors that could predict high-risk PH. Category-free (continuous) net reclassification improvement (NRI) and integrated discrimination improvement (IDI), were used to evaluate improvements in the accuracy of the prediction after adding a single nonlinear parameter into a model using only linear parameters. NRI is equal to the sum of the increasing probability for survivors and decreasing probability for non-survivors subtracted by the decreasing probability and increasing probability for non-survivors after adopting the updated model. IDI is defined as the average improvement of survival probability for all patients after adopting the updated model $[29,30]$. The significance of NRI and IDI statistics was based on approximate normal distributions. All statistical analyses were performed using R software 4.0.3 (http: / / www.r-project.org, accessed on 
10 October 2020) and SPSS version 25 for Windows (SPSS Inc., Chicago, IL, USA). The significance level was set at $0.05(p<0.05)$.

\section{Results}

\subsection{Patient Characteristics}

The clinical, echocardiographic, and hemodynamic variables of the enrolled patients are listed in Table 1. There were 20 patients in the high-risk group (group A) and 34 patients in the low-risk group (group B).

Table 1. Clinical Data of the patients.

\begin{tabular}{|c|c|c|c|}
\hline & $\begin{array}{l}\text { High-Risk Group } \\
\quad(\mathrm{N}=20)\end{array}$ & $\begin{array}{c}\text { Low-Risk Group } \\
\quad(\mathrm{N}=34)\end{array}$ & $p$ Value \\
\hline Age (years) & $43.80 \pm 10.70$ & $45.76 \pm 11.34$ & 0.533 \\
\hline Male, n (\%) & $9(45 \%)$ & $12(35 \%)$ & 0.480 \\
\hline $\mathrm{BMI}\left(\mathrm{kg} \cdot \mathrm{m}^{-2}\right)$ & $22.09 \pm 3.85$ & $24.21 \pm 4.41$ & 0.081 \\
\hline CAD, n (\%) & $1(5 \%)$ & $1(3 \%)$ & 1.000 \\
\hline $\mathrm{DM}, \mathrm{n}(\%)$ & $2(10 \%)$ & $3(9 \%)$ & 1.000 \\
\hline HTN, n (\%) & $1(5 \%)$ & $5(15 \%)$ & 0.395 \\
\hline Dyslipidemia, n (\%) & $1(5 \%)$ & $3(9 \%)$ & 1.000 \\
\hline PAH (WHO group 1) & $17(85 \%)$ & $18(53 \%)$ & 0.017 \\
\hline Hemoglobin (g/dL) & $13.72 \pm 3.15$ & $13.52 \pm 3.76$ & 0.835 \\
\hline Creatinine (mg/dL) & $1.15 \pm 0.67$ & $0.76 \pm 0.26$ & 0.024 \\
\hline Log NT-proBNP & $3.34 \pm 0.54$ & $2.52 \pm 0.54$ & $<0.001$ \\
\hline NT-proBNP (ng/dL) & 1510 (959 6428) & $292(116 \sim 1045)$ & $<0.001$ \\
\hline $\operatorname{LVEF}(\%)$ & $68.55 \pm 9.46$ & $68.62 \pm 10.07$ & 0.977 \\
\hline TRPG (mmHg) & $93.31 \pm 31.8$ & $64.67 \pm 28.10$ & 0.001 \\
\hline Pericardial effusion, $\mathrm{n}(\%)$ & $7(35 \%)$ & $1(3 \%)$ & 0.003 \\
\hline 6MWD (m) & $298.31 \pm 128.00$ & $367.42 \pm 120.32$ & 0.074 \\
\hline mPAP (mmHg) & $58.11 \pm 15.46$ & $47.44 \pm 15.27$ & 0.021 \\
\hline PVR (Wood Units) & $13.63 \pm 6.00$ & $8.24 \pm 4.23$ & 0.002 \\
\hline $\mathrm{CO}\left(\mathrm{L} \cdot \mathrm{min}^{-1}\right)$ & $3.71 \pm 1.59$ & $4.45 \pm 1.30$ & 0.081 \\
\hline $\mathrm{CI}\left(\mathrm{L} \cdot \mathrm{min}^{-1} \cdot \mathrm{m}^{2}\right)$ & $2.26 \pm 0.97$ & $2.75 \pm 0.86$ & 0.069 \\
\hline PAWP (mmHg) & $14.00 \pm 4.23$ & $12.09 \pm 3.69$ & 0.097 \\
\hline \multicolumn{4}{|l|}{ PAH specific medication } \\
\hline Sildenafil, n (\%) & $8(40 \%)$ & $15(44 \%)$ & 0.768 \\
\hline Macitentan, n (\%) & $3(15 \%)$ & $1(3 \%)$ & 0.138 \\
\hline Riociguat, n (\%) & $0(0 \%)$ & $6(18 \%)$ & 0.074 \\
\hline Bosentan, n (\%) & $2(10 \%)$ & $2(6 \%)$ & 0.622 \\
\hline Iloprost, n (\%) & $4(20 \%)$ & $1(3 \%)$ & 0.057 \\
\hline Epoprostenol, n (\%) & $1(5 \%)$ & $1(3 \%)$ & 1.000 \\
\hline
\end{tabular}

Abbreviation: $\mathrm{BMI}$, body mass index; CAD, coronary artery disease; DM, diabetes mellitus; HTN, hypertension; PAH, pulmonary arterial hypertension; NT-proBNP, N-terminal Pro-Brain Natriuretic Peptide; LVEF, left ventricular ejection fraction; TRPG, tricuspid regurgitation pressure gradient; 6MWD, 6-min-walk-distance; mPAP, mean pulmonary artery pressure; PVR, pulmonary vascular resistance; $\mathrm{CO}$, cardiac output; $\mathrm{CI}$, cardiac index; PAWP, pulmonary arterial wedge pressure.

Compared to group B, there were significantly more patients in group A, in WHO group 1, who had pericardial effusion. In addition, group A had higher levels of serum creatinine and NT-proBNP, and higher TRPG than group B. In pulmonary hemodynamic studies, PVR, and mPAP were significantly higher in group A. The PAH specific medication was listed in Table 1.

\subsection{Predictors of Interest: HRV Analysis}

In linear HRV analysis, group A had significantly lower LF/HF ratio compared to group B. Other linear parameters were comparable between the two groups (Table 2). In non-linear HRV analysis, group A had significantly lower DFA $\alpha 1$, slope 1-5, scale 5 and 
area 6-20 compared to group B (Table 2). The entropies over different time scales in group A and group B were shown in Figure 1.

Table 2. Holter parameters of the patients.

\begin{tabular}{|c|c|c|c|}
\hline & $\begin{array}{l}\text { High-Risk Group } \\
\qquad(\mathrm{N}=20)\end{array}$ & $\begin{array}{c}\text { Low-Risk Group } \\
(\mathbf{N}=34)\end{array}$ & $p$ Value \\
\hline \multicolumn{4}{|c|}{ Time Domain Analysis } \\
\hline Mean RR (ms) & 684.03 (605.77 795.63) & 748.63 (678.30 805.53) & 0.203 \\
\hline SDRR (ms) & $57.14(43.84 \sim 65.88)$ & $64.42(54.37 \sim 87.43)$ & 0.162 \\
\hline $\mathrm{pNN}_{20}(\%)$ & $19.17(9.20 \sim 26.67)$ & $20.86(13.94 \sim 36.88)$ & 0.463 \\
\hline $\mathrm{pNN}_{50}(\%)$ & $3.47(0.32 \sim 12.32)$ & $2.21(0.77 \sim 6.64)$ & 0.667 \\
\hline \multicolumn{4}{|c|}{ Frequency Domain Analysis } \\
\hline $\operatorname{VLF}\left(\mathrm{ms}^{-2}\right)$ & $172.56(46.43 \sim 543.01)$ & $384.16(169.56 \sim 604.98)$ & 0.062 \\
\hline $\mathrm{LF}\left(\mathrm{ms}^{-2}\right)$ & 64.99 (19.52 140.02) & $98.00(38.11 \sim 174.58)$ & 0.333 \\
\hline $\mathrm{HF}\left(\mathrm{ms}^{-2}\right)$ & $42.28(12.81 \sim 227.52)$ & $36.46(15.94 \sim 125.03)$ & 0.629 \\
\hline LF/HF ratio & $1.06(0.56 \sim 2.17)$ & $2.14(1.03 \sim 3.61)$ & 0.026 \\
\hline \multicolumn{4}{|c|}{ Detrended fluctuation analysis } \\
\hline DFA $\alpha 1$ & $0.92(0.56 \sim 1.05)$ & $1.04(0.89 \sim 1.23)$ & 0.028 \\
\hline DFA $\alpha 2$ & $1.12(1.01 \sim 1.19)$ & $1.11(1.03 \sim 1.17)$ & 0.900 \\
\hline \multicolumn{4}{|c|}{ Multiscale entropy } \\
\hline Slope 1-5 & $-0.008(-0.075 \sim 0.039)$ & $0.04(-0.03 \sim 0.07)$ & 0.038 \\
\hline Scale 5 & $1.01(0.73 \sim 1.14)$ & $1.22(1.06 \sim 1.36)$ & 0.002 \\
\hline Area 1-5 & $3.30(2.94 \sim 4.44)$ & $4.18(3.26 \sim 4.89)$ & 0.135 \\
\hline Area 6-20 & $15.94(12.48 \sim 18.40)$ & 18.89 (15.16 20.91) & 0.004 \\
\hline
\end{tabular}

Abbreviation: Mean RR, mean RR interval; SDRR, standard deviation of RR interval; $\mathrm{pNN}_{20}$, percentage of absolute differences in normal RR intervals greater than $20 \mathrm{~ms} ; \mathrm{pNN}_{50}$, percentage of absolute differences in normal RR intervals greater than 50 ms; VLF, very low frequency; LF, low frequency; HF, high frequency; DFA, detrended fluctuation analysis; area 1-5, area under the MSE curve for scale 1-5; area 6-20, area under the MSE curve for scale $6-20$

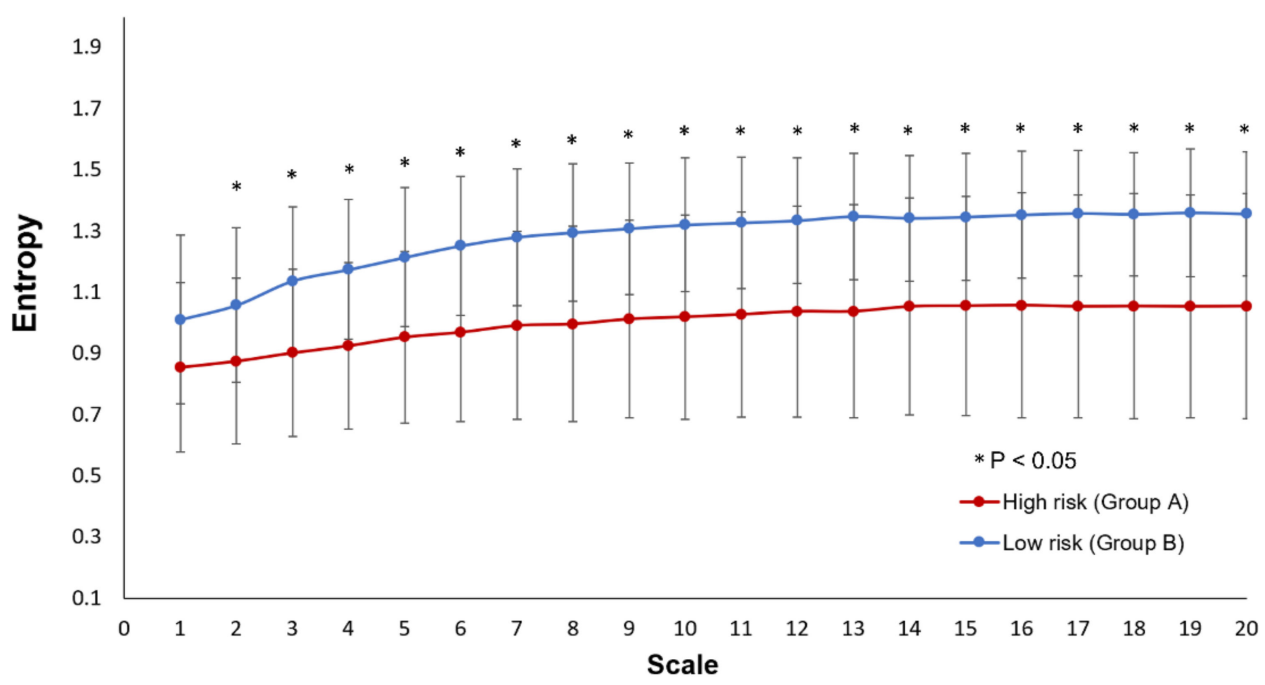

Figure 1. The entropy over different time scales in patients in high-risk group (Group A: red) and low-risk group (Group B: blue). ${ }^{*} p<0.05$, comparing entropy at different scale between high-risk and low-risk PH patients with independent $\mathrm{T}$ test.

3.2.1. Comparisons of Linear and Non-Linear HRV Parameters to Differentiate the High-Risk PH Patients

In ROC curve analysis, MSE scale 5 had highest predictive power to predict the highrisk PH patients. The area under curve (AUC) of MSE scale 5 was 0.758 . The AUCs of other linear and non-linear HRV parameters were 0.604 (mean RR), 0.616 (SDRR), 0.560 (pNN 20 ), 
$0.465\left(\mathrm{pNN}_{50}\right), 0.653$ (VLF), 0.579 (LF), 0.460 (HF), 0.682 (LH/HF ratio), 0.681 (DFA $\left.\alpha 1\right)$, 0.510 (DFA $\alpha 2), 0.671$ (slope 1-5), 0.623 (area 1-5), and 0.737 (area 6-20), which were shown in Figure 2.
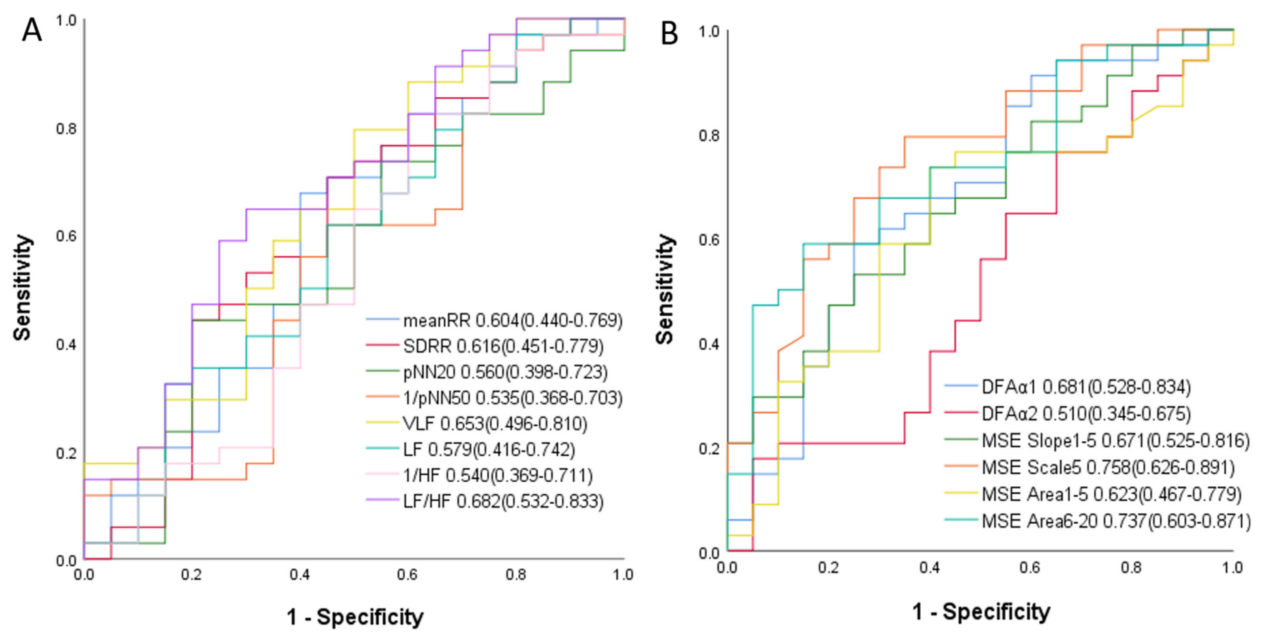

Figure 2. Analysis of the discrimination power of $H R V$ variables for $\mathrm{PH}$ risk stratification using receiver operating characteristic curve analysis. (A) ROC curves by using linear HRV parameters for predicting high-risk $\mathrm{PH}$ patients; (B) ROC curves by using heart rhythm complexity parameters for predicting high-risk PH patients. (Abbreviations: Mean RR, mean RR interval; SDRR, standard deviation of RR interval; $\mathrm{pNN}_{20}$, percentage of absolute differences in normal RR intervals greater than $20 \mathrm{~ms} ; \mathrm{pNN}_{50}$, percentage of absolute differences in normal RR intervals greater than $50 \mathrm{~ms}$; VLF, very low frequency; LF, low frequency; HF, high frequency; DFA, detrended fluctuation analysis; MSE, multiscale entropy.

\subsubsection{Logistic Regression Analysis to Predict the Presence of High-Risk PH}

In univariable logistic regression analysis, serum creatinine level, PAH, plasma NTproBNP level, mPAP, PVR, LF/HF ratio, DFA $\alpha 1$, MSE slope 1-5, scale 5, and area 6-20 were significantly associated with the presence of high-risk $\mathrm{PH}$. These parameters were further investigated in multivariable logistic regression analysis, which showed that plasma NTproBNP levels (odds ratio [OR]: 1.001, 95\% confidence interval [CI]: 1.000 1.002, $p=0.009$ ), and MSE scale 5 (OR: 0.009, 95\% CI: <0.001 0.324, $p=0.010$ ) were remained in the model and both NT-proBNP level and MSE scale 5 were significantly associated with the presence of high-risk PH (Table 3).

3.2.3. The Effect of Adding Heart Rhythm Complexity to the Linear HRV Parameters to Identify High-Risk PH Patients

In both NRI and IDI models, the MSE scale 5 significantly improved the discrimination power of all linear HRV parameters, including mean RR, SDRR, VLF, LF, HF, and LF/HF ratio. Area 6-20 significantly improved the discrimination power of mean RR, VLF, and HF in both NRI and IDI models, and SDRR, LF, and LF/HF ratio in IDI model. DFA $\alpha 1$ significantly improved the discrimination power of SDRR, VLF, LF, and HF in both the NRI and IDI models, and mean RR in the IDI model (Table 4).

Table 3. Univariable and multivariable logistic regression model to predict the high-risk group in pulmonary hypertension.

\begin{tabular}{cccc}
\hline & Univariable Logistic Regression & & Multivariable Logistic Regression \\
\hline & OR (95\% CI) & $p$ Value & OR (95\% CI) $\quad ~$ \\
\hline Age (Year) & $0.984(0.935 \sim 1.035)$ & 0.525 & \\
Sex (man) & $1.500(0.486 \sim 4.631)$ & 0.481 & \\
BMI $\left(\mathrm{kg} \cdot \mathrm{m}^{-2}\right)$ & $0.884(0.768 \sim 1.017)$ & 0.086 & \\
\hline
\end{tabular}


Table 3. Cont.

\begin{tabular}{|c|c|c|c|c|}
\hline \multicolumn{3}{|c|}{ Univariable Logistic Regression } & \multicolumn{2}{|c|}{ Multivariable Logistic Regression } \\
\hline & OR $(95 \% \mathrm{CI})$ & $p$ Value & OR $(95 \% \mathrm{CI})$ & $p$ Value \\
\hline PAH group 1 & $5.037(1.242 \sim 20.43)$ & 0.024 & & \\
\hline Creatinine (mg/dL) & $8.301(1.358 \sim 50.75)$ & 0.022 & & \\
\hline NT-ProBNP (ng/dl) & $1.001(1.000 \sim 1.002)$ & 0.019 & $1.001(1.000 \sim 1.002)$ & 0.009 \\
\hline $6 \mathrm{MWD}(\mathrm{m})$ & $0.995(0.990 \sim 1.001)$ & 0.080 & & \\
\hline mPAP (mmHg) & $1.046(1.005 \sim 1.089)$ & 0.029 & & \\
\hline $\mathrm{CI}\left(\mathrm{L} \cdot \mathrm{min}^{-1} \cdot \mathrm{m}^{2}\right)$ & $0.525(0.258 \sim 1.067)$ & 0.075 & & \\
\hline PVR (Wood Units) & $1.232(1.070 \sim 1.418)$ & 0.004 & & \\
\hline Mean RR (ms) & 0.997 (0.992 1.002) & 0.198 & & \\
\hline SDRR (ms) & $0.992(0.973 \sim 1.010)$ & 0.373 & & \\
\hline pNN20 (\%) & $0.993(0.961 \sim 1.025)$ & 0.647 & & \\
\hline pNN50 (\%) & $1.016(0.971 \sim 1.063)$ & 0.503 & & \\
\hline $\operatorname{VLF}\left(\mathrm{ms}^{-2}\right)$ & $0.998(0.996 \sim 1.000)$ & 0.081 & & \\
\hline $\operatorname{LF}\left(\mathrm{ms}^{-2}\right)$ & $0.999(0.997 \sim 1.002)$ & 0.543 & & \\
\hline $\mathrm{HF}\left(\mathrm{ms}^{-2}\right)$ & $1.000(0.999 \sim 1.001)$ & 0.858 & & \\
\hline $\mathrm{LF} / \mathrm{HF}$ ratio & $0.622(0.391 \sim 0.990)$ & 0.045 & & \\
\hline DFA $\alpha 1$ & $0.072(0.008 \sim 0.626)$ & 0.017 & & \\
\hline $\mathrm{DFA} \alpha 2$ & $0.457(0.006 \sim 33.761)$ & 0.721 & & \\
\hline Slope $1-5$ & $0.000(0.000 \sim 0.560)$ & 0.036 & & \\
\hline Scale 5 & $0.012(0.001 \sim 0.222)$ & 0.003 & $0.009(<0.001 \sim 0.324)$ & 0.010 \\
\hline Area 1-5 & 0.705 (0.418 1.189) & 0.190 & & \\
\hline Area 6-20 & 0.835 (0.714 0.977) & 0.024 & & \\
\hline
\end{tabular}

Abbreviation: BMI, body mass index; CAD, coronary artery disease; DM, diabetes mellitus; HTN, hypertension; PAH, pulmonary arterial hypertension; NT-proBNP, N-terminal Pro-Brain Natriuretic Peptide; LVEF, left ventricular ejection fraction; TRPG, tricuspid regurgitation pressure gradient; 6MWD, 6-min-walk-distance; MPAP, mean pulmonary artery pressure; $\mathrm{PVR}$, pulmonary vascular resistance; $\mathrm{CO}$, cardiac output; CI, cardiac index; PCWP, pulmonary capillary wedge pressure; Mean R-R, mean RR interval; SDRR, standard deviation of RR interval; $\mathrm{pNN}_{20}$, percentage of absolute differences in normal RR intervals greater than $20 \mathrm{~ms}$; $\mathrm{pNN}_{50}$, percentage of absolute differences in normal RR intervals greater than $50 \mathrm{~ms}$; VLF, very low frequency; LF, low frequency; HF, high frequency; DFA, detrended fluctuation analysis; area 1-5, area under the MSE curve for scale 1-5; area 6-20, area under the MSE curve for scale 6-20.

Table 4. AUC, NRI, and IDI models of linear parameters before and after adding DFA $\alpha 1$ and MSE parameters for risk stratification in pulmonary hypertension.

\begin{tabular}{|c|c|c|c|c|c|c|}
\hline Parameters & AUC & R Square & NRI & NRI $p$ Value & IDI & IDI $p$ Value \\
\hline Mean RR & 0.604 & 0.032 & & & & \\
\hline +Scale5 & 0.775 & 0.051 & 0.694 & 0.008 & 0.194 & 0.001 \\
\hline +Area 6-20 & 0.749 & 0.12 & 0.535 & 0.048 & 0.092 & 0.026 \\
\hline$+\mathrm{DFA} \alpha 1$ & 0.701 & 0.126 & 0.494 & 0.071 & 0.095 & 0.028 \\
\hline SDRR & 0.615 & 0.015 & & & & \\
\hline +Scale5 & 0.781 & 0.12 & 0.771 & 0.003 & 0.211 & 0.001 \\
\hline +Area 6-20 & 0.731 & 0.121 & 0.494 & 0.071 & 0.107 & 0.014 \\
\hline$+\mathrm{DFA} \alpha 1$ & 0.681 & 0.123 & 0.535 & 0.048 & 0.108 & 0.017 \\
\hline VLF & 0.653 & 0.061 & & & & \\
\hline +Scale5 & 0.782 & 0.117 & 0.535 & 0.048 & 0.171 & 0.002 \\
\hline +Area 6-20 & 0.725 & 0.147 & 0.653 & 0.014 & 0.082 & 0.035 \\
\hline$+\mathrm{DFA} \alpha 1$ & 0.699 & 0.145 & 0.694 & 0.008 & 0.084 & 0.037 \\
\hline LF & 0.579 & 0.008 & & & & \\
\hline +Scale5 & 0.768 & 0.086 & 0.771 & 0.003 & 0.209 & 0.001 \\
\hline +Area 6-20 & 0.731 & 0.118 & 0.494 & 0.071 & 0.112 & 0.012 \\
\hline$+\mathrm{DFA} \alpha 1$ & 0.694 & 0.134 & 0.553 & 0.042 & 0.129 & 0.01 \\
\hline $\mathrm{HF}$ & 0.54 & 0.001 & & & & \\
\hline +Scale5 & 0.76 & 0.029 & 0.871 & 0.001 & 0.221 & $<0.001$ \\
\hline +Area 6-20 & 0.734 & 0.116 & 0.553 & 0.042 & 0.118 & 0.01 \\
\hline$+\mathrm{DFA} \alpha 1$ & 0.694 & 0.129 & 0.612 & 0.023 & 0.132 & 0.009 \\
\hline
\end{tabular}


Table 4. Cont.

\begin{tabular}{ccccccc}
\hline Parameters & AUC & R Square & NRI & NRI $p$ Value & IDI & IDI $p$ Value \\
\hline LF/HF ratio & 0.682 & 0.075 & & & & \\
+Scale5 & 0.806 & 0.077 & 0.771 & 0.003 & 0.184 & 0.001 \\
+Area 6-20 & 0.76 & 0.156 & 0.394 & 0.154 & 0.068 & 0.039 \\
+DFA $\alpha 1$ & 0.718 & 0.114 & 0.335 & 0.228 & 0.027 & 0.19 \\
\hline
\end{tabular}

Abbreviation: Mean RR, mean RR interval; SDRR, standard deviation of RR interval; VLF, very low frequency; LF, low frequency; HF, high frequency; DFA, detrended fluctuation analysis.

\section{Discussion}

The main finding of this study was that heart rhythm complexity was significantly depressed in high-risk $\mathrm{PH}$ patients. In addition, adding heart rhythm complexity predictors to traditional linear HRV parameters improved the power to predict high-risk PH patients. This is the first study to demonstrate an association between heart rhythm complexity and severity of $\mathrm{PH}$, and the better performance of heart rhythm complexity in identifying high-risk $\mathrm{PH}$ patients than traditional HRV parameters.

$\mathrm{PH}$ is a critical disease, which needs an early diagnosis and timely management. Patients classified as being at high risk according to the 2015 ESC/ERS PH guidelines have a worse prognosis compared to patients at low risk. Sitbon et al. demonstrated that poor functional status was associated with poor outcomes. In their study, $\mathrm{PH}$ patients in WHO functional class IV and those in class III with severely compromised hemodynamics had the worst outcomes [19]. Previous studies have demonstrated that early interventions including both pharmacological and multidisciplinary team care can improve the outcomes of $\mathrm{PH}$ patients, even those with severe disease and poor functional status [5]. Therefore, identifying high-risk patients is essential for the management of $\mathrm{PH}$. Several survival prediction models have been proposed for $\mathrm{PH}$ patients; however, they are complex and difficult to use [31]. Currently, the 2015 ESC/ERS PH guidelines advocate assessing the risk of $\mathrm{PH}$ by using a combination of several different tools, and this method is widely used in daily practice [1]. However, risk assessment requires invasive right heart catheterization, which is difficult to apply in frequent monitoring during follow-up. Therefore, there is still a strong unmet need for an easy-to-use tool to allow for both timely and continuous monitoring of disease status to improve the clinical care of $\mathrm{PH}$ patients.

$\mathrm{HRV}$ is a useful non-invasive tool, which has been studied in many diseases, including coronary artery disease, heart failure, and even pulmonary hypertension [32-34]. It has been correlated with autonomic dysfunction and used as an outcome predictor. Porte et al. demonstrated that heart rate complexity parameters decreased due to sympathetic activation during postural change [35]. Another study showed that sympathetic activation during senescence was associated with impaired heart rate complexity [36]. These evidences supported that the usefulness of heart rate complexity in monitoring sympathovagal balance. Pulmonary hypertension is characterized by increased pulmonary artery pressure leading to right ventricular failure [37]. The serum norepinephrine increased in patients with PAH similar to those with congestive heart failure as the indicator of cardiac sympathetic activation [38]. Furthermore, sympathetic activation has also been correlated with the severity of $\mathrm{PH}[39,40]$. Several studies also showing that measuring autonomic system regulation using HRV could be a predictor of disease severity and long-term outcomes in PH [41-44]. Since that, overactivation of sympathetic systems is likely to be one of the major reasons explaining the worse HRV and complexity in severe PH patients. Bienias et al. demonstrated that patients with arterial or chronic thromboembolic PH had significantly impaired heart rate turbulence, a linear HRV parameter [45]. Recently, Peng et al. proposed the heart rhythm complexity derived from two non-linear parameters of HRV, DFA, and MSE, to evaluate complexity change in the biological systems $[26,28,46]$. Heart rhythm complexity was shown to have better efficacy and predictive power for various diseases than traditional HRV [14,47]. 
Heart rhythm complexity measures the complexity of changes in the R-R interval, which contains detailed information derived from heart rate dynamics. Once a biological system has become diseased, the complexity breaks down, and non-linear HRV analysis, can detect subtle changes at an early stage [48]. In a retrospective study, abnormal DFA $\alpha 1$ in asymptomatic heart failure patients was associated with the onset of heart failure years in advance of the first clinical event $[49,50]$. Tsai et al. recently demonstrated that heart rhythm complexity had a better prognostic value for cardiovascular events in patients undergoing peritoneal dialysis compared with linear HRV analysis [47]. In recent years, heart rhythm complexity was extensively studied in many fields, including left heart failure [51], post-infarction myocardial function [52], patients undergoing dialysis [12,47,53], severity of abdominal aorta calcification [54], primary aldosteronism [24], stroke [55], and $\mathrm{PH}$ [56]. These studies support the importance of heart rhythm complexity in clinical practice and its potential role in disease risk stratification. In the present study, we demonstrated that heart rhythm complexity parameters, especially MSE scale 5, were significantly associated with $\mathrm{PH}$ disease severity and could be used in PH risk stratification. To the best of our knowledge, this is the first study to apply heart rhythm complexity to the prediction of $\mathrm{PH}$ disease severity. Although the improvement of the complexity can be attribute to not only the enhanced complexity characteristics but the magnitude of HRV [57], combining different parameters of MSE can give us better information related to the "quality" (complexity) or the "quantity" (magnitude of HRV) changes [58]. Furthermore, model-free complexity can assess the embedded space with variable scales grouped by the K-nearest-neighbor to avoid coarse-graining that may introduce bias due to the fixed dimensions as well as the aliasing filter effect $[57,59]$. Recently, the local version of the sample entropy was proposed to eliminate the nonstationary effect on the results of complexity analysis [60]. The research by using those new methods warrants further study. In addition, the cardiopulmonary coupling is another important issue in the HRV analysis focusing on the interaction between cardiovascular and cardiorespiratory systems. The cardiorespiratory coupling between the systems is thought to be with each other in a nonlinear way [61]. MSE has been used to evaluate the cardiorespiratory coupling and the asynchrony. Platiša et al. demonstrated that primary alterations in the regularity of cardiac rhythm resulted in changes in the regularity of the respiratory rhythm in heart failure patients [62]. However, there were limited studies investigating the cardiorespiratory coupling in $\mathrm{PH}$ patients. Further studies may be needed to integrate the role of cardiorespiratory coupling in $\mathrm{PH}$ patients.

Compared with heart rhythm complexity, linear HRV parameters, including SDRR, SDRR index, VLF, LF/HF ratio, and heart rate turbulence have been widely studied to assess PH [45,63]. Recent studies have also demonstrated an association between impaired linear HRV parameter, SDRR, and PH disease severity markers, including impaired WHO functional status, decreased 6MWD, impaired tricuspid annular plane systolic excursion, right ventricular systolic function, higher TRPG, and NT-proBNP level [64-66]. In this study, we first demonstrated a better association between heart rhythm complexity and $\mathrm{PH}$ disease severity compared to traditional HRV analysis. Second, the discrimination power of linear HRV for PH disease severity improved significantly after combining heart rhythm complexity parameters. The combination of linear and non-linear HRV parameters to form a new predictive model may have further improved its risk stratification ability and outcome prediction.

There are several limitations to this study. First, this is a pilot study. The number of cases was small, and further studies are needed to validate the results. In addition, model-free complexity analysis or entropy with local characteristics can preserve more information instead of a one-fit-all algorithm. Those methods should be included for a large-scale study to probe the underlying pathophysiological mechanisms related to the changes of the complexity of the PH patients. Second, we only enrolled $\mathrm{PH}$ patients in WHO group 1 and group 4, and future studies should enroll different groups of $\mathrm{PH}$ patients to investigate the potential application of HRV in these patients. Third, this pilot study is a cross-sectional design and lacks clinical long-term follow-up data. A prospective cohort 
study with clinical end-point follow-up is needed to confirm the utility of heart rhythm complexity on clinical outcome predictions.

\section{Conclusions}

This study demonstrated that high-risk PH patients had worse heart rhythm complexity. MSE scale 5 had the best discrimination power to predict high-risk $\mathrm{PH}$ patients. Moreover, adding MSE scale 5, area 6-20 or DFA $\alpha 1$ to linear HRV parameters significantly improved the predictive power for high-risk $\mathrm{PH}$ patients. Heart rhythm complexity can potentially be used as (i) an indicator of $\mathrm{PH}$ disease severity, and (ii) to stratify the risk of $\mathrm{PH}$.

Author Contributions: Conceptualization, Y.-H.L.; methodology, S.-Y.T.; software, C.-H.T.; validation, H.-P.M. and C.-S.H.; formal analysis, H.-P.M. and C.L.; investigation, M.-T.L. and Y.-T.L.; resources, H.-H.H. and P.-H.K.; data curation, Y.-W.C.; writing—original draft preparation, S.-Y.T.; writing-review and editing, C.-H.T., C.L. and Y.-H.L.; visualization, S.-Y.T.; supervision, C.-K.P.; project administration, C.-K.W. and Y.-H.L.; funding acquisition, Y.-H.L. All authors have read and agreed to the published version of the manuscript.

Funding: This study was supported by grants from the National Taiwan University Hospital (NTUH 109-A141) and Department of Health, Executive Yuan, R.O.C. (PTH 107-43, PTH 108-29, PTH 109-13). M.-T.L. and C.L. gratefully acknowledge support from the Ministry of Science and Technology (Grant Nos. 104-3115-E-008-001 and 104-2745-B-008-001) and the joint foundations (Grant Nos. 103CGHNCU-A1, VGHUST103-G1-3-3). The funders had no role in study design, data collection and analysis, decision to publish, or preparation of the manuscript.

Institutional Review Board Statement: The study was conducted according to the guidelines of the Declaration of Helsinki, and approved by the Institutional Review Board (or Ethics Committee) of National Taiwan University Hospital (protocol code NTUH REC No. 201003042R and date of approval: 4 March 2010).

Informed Consent Statement: Informed consent was obtained from all subjects involved in the study.

Data Availability Statement: The data presented in this study are available on request from the corresponding author. The data are not publicly available due to privacy.

Acknowledgments: We thank Hsing-Fen Lin for his consultation with the statistical analysis during the completion of the manuscript.

Conflicts of Interest: The authors declare no conflict of interest.

\section{References}

1. Galie, N.; Humbert, M.; Vachiery, J.L.; Gibbs, S.; Lang, I.; Torbicki, A.; Simonneau, G.; Peacock, A.; Vonk Noordegraaf, A.; Beghetti, M.; et al. 2015 ESC/ERS Guidelines for the Diagnosis and Treatment of Pulmonary Hypertension. Rev. Esp. Cardiol. (Engl. Ed.) 2016, 69, 177. [CrossRef] [PubMed]

2. Lilienfeld, D.E.; Rubin, L.J. Mortality from primary pulmonary hypertension in the United States, 1979-1996. Chest 2000, 117, 796-800. [CrossRef] [PubMed]

3. Ghofrani, H.A.; Wiedemann, R.; Rose, F.; Olschewski, H.; Schermuly, R.T.; Weissmann, N.; Seeger, W.; Grimminger, F. Combination therapy with oral sildenafil and inhaled iloprost for severe pulmonary hypertension. Ann. Intern. Med. 2002, 136, 515-522. [CrossRef] [PubMed]

4. Hoeper, M.M.; Faulenbach, C.; Golpon, H.; Winkler, J.; Welte, T.; Niedermeyer, J. Combination therapy with bosentan and sildenafil in idiopathic pulmonary arterial hypertension. Eur. Respir. J. 2004, 24, 1007-1010. [CrossRef]

5. Galie, N.; Humbert, M.; Vachiery, J.L.; Gibbs, S.; Lang, I.; Torbicki, A.; Simonneau, G.; Peacock, A.; Vonk Noordegraaf, A.; Beghetti, M.; et al. 2015 ESC/ERS Guidelines for the diagnosis and treatment of pulmonary hypertension: The Joint Task Force for the Diagnosis and Treatment of Pulmonary Hypertension of the European Society of Cardiology (ESC) and the European Respiratory Society (ERS): Endorsed by: Association for European Paediatric and Congenital Cardiology (AEPC), International Society for Heart and Lung Transplantation (ISHLT). Eur. Heart J. 2016, 37, 67-119. [CrossRef]

6. Humbert, M.; Sitbon, O.; Chaouat, A.; Bertocchi, M.; Habib, G.; Gressin, V.; Yaïci, A.; Weitzenblum, E.; Cordier, J.-F.; Chabot, F.; et al. Survival in Patients With Idiopathic, Familial, and Anorexigen-Associated Pulmonary Arterial Hypertension in the Modern Management Era. Circulation 2010, 122, 156-163. [CrossRef]

7. Wang, L.Y.; Lee, K.T.; Lin, C.P.; Hsu, L.A.; Wang, C.L.; Hsu, T.S.; Ho, W.J. Long-Term Survival of Patients with Pulmonary Arterial Hypertension at a Single Center in Taiwan. Acta. Cardiol. Sin. 2017, 33, 498-509. 
8. Benza, R.L.; Miller, D.P.; Barst, R.J.; Badesch, D.B.; Frost, A.E.; McGoon, M.D. An Evaluation of Long-term Survival From Time of Diagnosis in Pulmonary Arterial Hypertension From the REVEAL Registry. Chest 2012, 142, 448-456. [CrossRef]

9. Hoeper, M.M.; Pittrow, D.; Opitz, C.; Gibbs, J.S.R.; Rosenkranz, S.; Grünig, E.; Olsson, K.M.; Huscher, D. Risk assessment in pulmonary arterial hypertension. Eur. Respir. J. 2018, 51, 1702606. [CrossRef]

10. Raina, A.; Humbert, M. Risk assessment in pulmonary arterial hypertension. Eur. Respir. Rev. 2016, 25, 390-398. [CrossRef]

11. Ho, Y.L.; Lin, C.; Lin, Y.H.; Lo, M.T. The prognostic value of non-linear analysis of heart rate variability in patients with congestive heart failure-a pilot study of multiscale entropy. PLoS ONE 2011, 6, e18699. [CrossRef]

12. Ferrario, M.; Raimann, J.G.; Larive, B.; Pierratos, A.; Thijssen, S.; Rajagopalan, S.; Greene, T.; Cerutti, S.; Beck, G.; Chan, C.; et al. Non-Linear Heart Rate Variability Indices in the Frequent Hemodialysis Network Trials of Chronic Hemodialysis Patients. Blood Purif. 2015, 40, 99-108. [CrossRef]

13. Tsai, C.H.; Ma, H.P.; Lin, Y.T.; Hung, C.S.; Hsieh, M.C.; Chang, T.Y.; Kuo, P.H.; Lin, C.; Lo, M.T.; Hsu, H.H.; et al. Heart Rhythm Complexity Impairment in Patients with Pulmonary Hypertension. Sci. Rep. 2019, 9, 10710. [CrossRef]

14. Makikallio, T.H.; Huikuri, H.V.; Hintze, U.; Videbaek, J.; Mitrani, R.D.; Castellanos, A.; Myerburg, R.J.; Moller, M.; Group, D.S. Fractal analysis and time- and frequency-domain measures of heart rate variability as predictors of mortality in patients with heart failure. Am. J. Cardiol. 2001, 87, 178-182. [CrossRef]

15. Humbert, M. Pulmonary arterial hypertension and chronic thromboembolic pulmonary hypertension: Pathophysiology. Eur. Respir. Rev. 2010, 19, 59-63. [CrossRef]

16. Thenappan, T.; Ormiston, M.L.; Ryan, J.J.; Archer, S.L. Pulmonary arterial hypertension: Pathogenesis and clinical management. BMJ 2018, 360, j5492. [CrossRef]

17. Glanville, A.R.; Burke, C.M.; Theodore, J.; Robin, E.D. Primary pulmonary hypertension. Length of survival in patients referred for heart-lung transplantation. Chest 1987, 91, 675-681. [CrossRef]

18. Montani, D.; O'Callaghan, D.S.; Jais, X.; Savale, L.; Natali, D.; Redzepi, A.; Hoette, S.; Parent, F.; Sitbon, O.; Simonneau, G.; et al. Implementing the ESC/ERS pulmonary hypertension guidelines: Real-life cases from a national referral centre. Eur. Respir. Rev. 2009, 18, 272-290. [CrossRef]

19. Sitbon, O.; Simonneau, G. Optimal management of severe pulmonary arterial hypertension. Eur. Respir. Rev. 2011, 20, 254-261. [CrossRef]

20. Von Elm, E.; Altman, D.G.; Egger, M.; Pocock, S.J.; Gotzsche, P.C.; Vandenbroucke, J.P.; Initiative, S. The Strengthening the Reporting of Observational Studies in Epidemiology (STROBE) statement: Guidelines for reporting observational studies. Ann. Intern. Med. 2007, 147, 573-577. [CrossRef]

21. Mitchell, C.; Rahko, P.S.; Blauwet, L.A.; Canaday, B.; Finstuen, J.A.; Foster, M.C.; Horton, K.; Ogunyankin, K.O.; Palma, R.A.; Velazquez, E.J. Guidelines for Performing a Comprehensive Transthoracic Echocardiographic Examination in Adults: Recommendations from the American Society of Echocardiography. J. Am. Soc. Echocardiogr. 2019, 32, 1-64. [CrossRef] [PubMed]

22. Magagnin, V.; Bassani, T.; Bari, V.; Turiel, M.; Maestri, R.; Pinna, G.D.; Porta, A. Non-stationarities significantly distort short-term spectral, symbolic and entropy heart rate variability indices. Physiol. Meas. 2011, 32, 1775-1786. [CrossRef] [PubMed]

23. Lin, C.; Yeh, C.H.; Wang, C.Y.; Shi, W.; Serafico, B.M.F.; Wang, C.H.; Juan, C.H.; Vincent Young, H.W.; Lin, Y.J.; Yeh, H.M.; et al. Robust Fetal Heart Beat Detection via R-Peak Intervals Distribution. IEEE Trans. Biomed. Eng. 2019, 66, 3310-3319. [CrossRef] [PubMed]

24. Lin, Y.H.; Wu, V.C.; Lo, M.T.; Wu, X.M.; Hung, C.S.; Wu, K.D.; Lin, C.; Ho, Y.L.; Stowasser, M.; Peng, C.K. Reversible heart rhythm complexity impairment in patients with primary aldosteronism. Sci. Rep. 2015, 5, 11249. [CrossRef] [PubMed]

25. Heart rate variability: Standards of measurement, physiological interpretation and clinical use. Task Force of the European Society of Cardiology and the North American Society of Pacing and Electrophysiology. Circulation 1996, 93, 1043-1065.

26. Peng, C.K.; Havlin, S.; Stanley, H.E.; Goldberger, A.L. Quantification of scaling exponents and crossover phenomena in nonstationary heartbeat time series. Chaos 1995, 5, 82-87. [CrossRef] [PubMed]

27. Peng, C.K.; Havlin, S.; Hausdorff, J.M.; Mietus, J.E.; Stanley, H.E.; Goldberger, A.L. Fractal mechanisms and heart rate dynamics: Long-range correlations and their breakdown with disease. J. Electrocardiol. 1995, 28, 59-65. [CrossRef]

28. Costa, M.; Goldberger, A.L.; Peng, C.K. Multiscale entropy analysis of biological signals. Phys. Rev. E Stat. Nonlin. Soft Matter Phys. 2005, 71, 021906. [CrossRef]

29. Pencina, M.J.; D'Agostino, R.B., Sr.; D'Agostino, R.B., Jr.; Vasan, R.S. Evaluating the added predictive ability of a new marker: From area under the ROC curve to reclassification and beyond. Stat. Med. 2008, 27, 157-172. [CrossRef]

30. Pencina, M.J.; D'Agostino, R.B., Sr.; Steyerberg, E.W. Extensions of net reclassification improvement calculations to measure usefulness of new biomarkers. Stat. Med. 2011, 30, 11-21. [CrossRef]

31. Ling, Y.; Johnson, M.K.; Kiely, D.G.; Condliffe, R.; Elliot, C.A.; Gibbs, J.S.R.; Howard, L.S.; Pepke-Zaba, J.; Sheares, K.K.K.; Corris, P.A.; et al. Changing Demographics, Epidemiology, and Survival of Incident Pulmonary Arterial Hypertension. Am. J. Respir. Crit. Care Med. 2012, 186, 790-796. [CrossRef]

32. Casolo, G.; Balli, E.; Taddei, T.; Amuhasi, J.; Gori, C. Decreased spontaneous heart rate variability in congestive heart failure. Am. J. Cardiol. 1989, 64, 1162-1167. [CrossRef]

33. Goncalves, H.; Henriques-Coelho, T.; Bernardes, J.; Rocha, A.P.; Brandao-Nogueira, A.; Leite-Moreira, A. Analysis of heart rate variability in a rat model of induced pulmonary hypertension. Med. Eng. Phys. 2010, 32, 746-752. [CrossRef] 
34. Huikuri, H.V.; Jokinen, V.; Syvanne, M.; Nieminen, M.S.; Airaksinen, K.E.; Ikaheimo, M.J.; Koistinen, J.M.; Kauma, H.; Kesaniemi, A.Y.; Majahalme, S.; et al. Heart rate variability and progression of coronary atherosclerosis. Arter. Thromb. Vasc. Biol. 1999, 19, 1979-1985. [CrossRef]

35. Porta, A.; Gnecchi-Ruscone, T.; Tobaldini, E.; Guzzetti, S.; Furlan, R.; Montano, N. Progressive decrease of heart period variability entropy-based complexity during graded head-up tilt. J. Appl. Physiol. 2007, 103, 1143-1149. [CrossRef]

36. Catai, A.M.; Takahashi, A.; Perseguini, N.M.; Milan, J.C.; Minatel, V.; Rehder-Santos, P.; Marchi, A.; Bari, V.; Porta, A. Effect of the postural challenge on the dependence of the cardiovascular control complexity on age. Entropy 2014, 16, 6686-6704. [CrossRef]

37. Ryan, J.J.; Archer, S.L. The right ventricle in pulmonary arterial hypertension: Disorders of metabolism, angiogenesis and adrenergic signaling in right ventricular failure. Circ. Res. 2014, 115, 176-188. [CrossRef]

38. Mak, S.; Witte, K.K.; Al-Hesayen, A.; Granton, J.J.; Parker, J.D. Cardiac sympathetic activation in patients with pulmonary arterial hypertension. Am. J. Physiol. Regul. Integr. Comp. Physiol. 2012, 302, R1153-R1157. [CrossRef]

39. Ciarka, A.; Doan, V.; Velez-Roa, S.; Naeije, R.; van de Borne, P. Prognostic significance of sympathetic nervous system activation in pulmonary arterial hypertension. Am. J. Respir. Crit. Care. Med. 2010, 181, 1269-1275. [CrossRef]

40. Velez-Roa, S.; Ciarka, A.; Najem, B.; Vachiery, J.L.; Naeije, R.; van de Borne, P. Increased sympathetic nerve activity in pulmonary artery hypertension. Circulation 2004, 110, 1308-1312. [CrossRef]

41. Isobe-Sasaki, Y.; Fukuda, M.; Ogiyama, Y.; Sato, R.; Miura, T.; Fuwa, D.; Mizuno, M.; Matsuoka, T.; Shibata, H.; Ito, H.; et al. Sodium balance, circadian BP rhythm, heart rate variability, and intrarenal renin-angiotensin-aldosterone and dopaminergic systems in acute phase of ARB therapy. Physiol. Rep. 2017, 5, e13309. [CrossRef]

42. Saul, J.P.; Arai, Y.; Berger, R.D.; Lilly, L.S.; Colucci, W.S.; Cohen, R.J. Assessment of autonomic regulation in chronic congestive heart failure by heart rate spectral analysis. Am. J. Cardiol. 1988, 61, 1292-1299. [CrossRef]

43. Florea, V.G.; Cohn, J.N. The autonomic nervous system and heart failure. Circ. Res. 2014, 114, 1815-1826. [CrossRef]

44. Vaillancourt, M.; Chia, P.; Sarji, S.; Nguyen, J.; Hoftman, N.; Ruffenach, G.; Eghbali, M.; Mahajan, A.; Umar, S. Autonomic nervous system involvement in pulmonary arterial hypertension. Respir. Res. 2017, 18, 201. [CrossRef]

45. Bienias, P.; Kostrubiec, M.; Rymarczyk, Z.; Korczak, D.; Ciurzynski, M.; Kurzyna, M.; Torbicki, A.; Fijalkowska, A.; Pruszczyk, P. Severity of arterial and chronic thromboembolic pulmonary hypertension is associated with impairment of heart rate turbulence. Ann. Noninvasive Electrocardiol. 2015, 20, 69-78. [CrossRef]

46. Costa, M.; Goldberger, A.L.; Peng, C.K. Multiscale entropy analysis of complex physiologic time series. Phys. Rev. Lett. 2002, 89, 068102. [CrossRef]

47. Tsai, C.H.; Huang, J.W.; Lin, C.; Ma, H.P.; Lo, M.T.; Liu, L.D.; Lin, L.Y.; Lin, C.T.; Hung, C.S.; Peng, C.K.; et al. Heart Rhythm Complexity Predicts Long-Term Cardiovascular Outcomes in Peritoneal Dialysis Patients: A Prospective Cohort Study. J. Am. Heart Assoc. 2020, 9, e013036. [CrossRef]

48. Busa, M.A.; van Emmerik, R.E.A. Multiscale entropy: A tool for understanding the complexity of postural control. J. Sport Health Sci. 2016, 5, 44-51. [CrossRef]

49. Patel, V.N.; Pierce, B.R.; Bodapati, R.K.; Brown, D.L.; Ives, D.G.; Stein, P.K. Association of Holter-Derived Heart Rate Variability Parameters with the Development of Congestive Heart Failure in the Cardiovascular Health Study. JACC Heart Fail. 2017, 5 , 423-431. [CrossRef]

50. Binkley, P.F. Promise of a New Role for Heart Rate Variability in the Clinical Management of Patients with Heart Failure. JACC Heart Fail. 2017, 5, 432-434. [CrossRef]

51. Tsuji, H.; Larson, M.G.; Venditti, F.J., Jr.; Manders, E.S.; Evans, J.C.; Feldman, C.L.; Levy, D. Impact of reduced heart rate variability on risk for cardiac events. The Framingham Heart Study. Circulation 1996, 94, 2850-2855. [CrossRef] [PubMed]

52. Chiu, H.C.; Ma, H.P.; Lin, C.; Lo, M.T.; Lin, L.Y.; Wu, C.K.; Chiang, J.Y.; Lee, J.K.; Hung, C.S.; Wang, T.D.; et al. Serial heart rhythm complexity changes in patients with anterior wall ST segment elevation myocardial infarction. Sci. Rep. 2017, 7, 43507. [CrossRef]

53. Chiang, J.Y.; Huang, J.W.; Lin, L.Y.; Chang, C.H.; Chu, F.Y.; Lin, Y.H.; Wu, C.K.; Lee, J.K.; Hwang, J.J.; Lin, J.L.; et al. Detrended Fluctuation Analysis of Heart Rate Dynamics Is an Important Prognostic Factor in Patients with End-Stage Renal Disease Receiving Peritoneal Dialysis. PLoS ONE 2016, 11, e0147282. [CrossRef] [PubMed]

54. Tsai, C.H.; Lin, C.; Ho, Y.H.; Lo, M.T.; Liu, L.D.; Lin, C.T.; Huang, J.W.; Peng, C.K.; Lin, Y.H. The association between heart rhythm complexity and the severity of abdominal aorta calcification in peritoneal dialysis patients. Sci. Rep. 2018, 8, 15627. [CrossRef] [PubMed]

55. Tang, S.C.; Jen, H.I.; Lin, Y.H.; Hung, C.S.; Jou, W.J.; Huang, P.W.; Shieh, J.S.; Ho, Y.L.; Lai, D.M.; Wu, A.Y.; et al. Complexity of heart rate variability predicts outcome in intensive care unit admitted patients with acute stroke. J. Neurol. Neurosurg. Psychiatry 2015, 86, 95-100. [CrossRef] [PubMed]

56. Folino, A.F.; Bobbo, F.; Schiraldi, C.; Tona, F.; Romano, S.; Buja, G.; Bellotto, F. Ventricular arrhythmias and autonomic profile in patients with primary pulmonary hypertension. Lung 2003, 181, 321-328. [CrossRef] [PubMed]

57. Valencia, J.F.; Porta, A.; Vallverdu, M.; Claria, F.; Baranowski, R.; Orlowska-Baranowska, E.; Caminal, P. Refined multiscale entropy: Application to 24-h Holter recordings of heart period variability in healthy and aortic stenosis subjects. IEEE Trans. Biomed. Eng. 2009, 56, 2202-2213. [CrossRef]

58. Yeh, C.H.; Juan, C.H.; Yeh, H.M.; Wang, C.Y.; Young, H.V.; Lin, J.L.; Lin, C.; Lin, L.Y.; Lo, M.T. The critical role of respiratory sinus arrhythmia on temporal cardiac dynamics. J. Appl. Physiol. 2019, 127, 1733-1741. [CrossRef] 
59. Porta, A.; De Maria, B.; Bari, V.; Marchi, A.; Faes, L. Are Nonlinear Model-Free Conditional Entropy Approaches for the Assessment of Cardiac Control Complexity Superior to the Linear Model-Based One? IEEE Trans. Biomed. Eng. 2017, 64, 1287-1296. [CrossRef]

60. Porta, A.; Bari, V.; De Maria, B.; Cairo, B.; Vaini, E.; Malacarne, M.; Pagani, M.; Lucini, D. On the Relevance of Computing a Local Version of Sample Entropy in Cardiovascular Control Analysis. IEEE Trans. Biomed. Eng. 2019, 66, 623-631. [CrossRef]

61. Schulz, S.; Adochiei, F.C.; Edu, I.R.; Schroeder, R.; Costin, H.; Bar, K.J.; Voss, A. Cardiovascular and cardiorespiratory coupling analyses: A review. Philos. Trans. A Math. Phys. Eng. Sci. 2013, 371, 20120191. [CrossRef]

62. Platisa, M.M.; Radovanovic, N.N.; Kalauzi, A.; Milasinovic, G.; Pavlovic, S.U. Multiscale Entropy Analysis: Application to Cardio-Respiratory Coupling. Entropy 2020, 22, 1042. [CrossRef]

63. Witte, C.; Meyer Zur Heide Genannt Meyer-Arend, J.U.; Andrie, R.; Schrickel, J.W.; Hammerstingl, C.; Schwab, J.O.; Nickenig, G.; Skowasch, D.; Pizarro, C. Heart Rate Variability and Arrhythmic Burden in Pulmonary Hypertension. Adv. Exp. Med. Biol. 2016, 934, 9-22. [CrossRef]

64. Bienias, P.; Ciurzynski, M.; Kostrubiec, M.; Rymarczyk, Z.; Kurzyna, M.; Korczak, D.; Roik, M.; Torbicki, A.; Fijalkowska, A.; Pruszczyk, P. Functional class and type of pulmonary hypertension determinate severity of cardiac autonomic dysfunction assessed by heart rate variability and turbulence. Acta. Cardiol. 2015, 70, 286-296. [CrossRef]

65. Semen, K.; Solovey, L.; Karapinka, M.; Yelisyeyeva, O. Heart rate variability: Possible implications for management of pulmonary arterial hypertension patients. Eur. Respir. J. 2012, 40, P970.

66. Andersen, M.Ø.; Diederichsen, S.Z.; Svendsen, J.H.; Carlsen, J. Heart Rate Variability as Assessed with Long-Term Continuous Cardiac Monitoring in Pulmonary Hypertension. J. Am. Coll. Cardiol. 2020, 75, 2088. [CrossRef] 